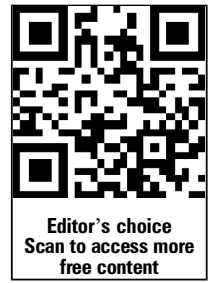

free content

TOP TEN ARTICLE

\title{
Hypoxia, haemorrhage and hypotension: the interface between emergency medicine and intensive care medicine
}

\author{
Bernard A Foëx
}

\begin{abstract}
Correspondence to Bernard A Foëx, Emergency Department, Manchester Royal Infirmary, Oxford Road, Manchester M13 9WL, UK; Bernard.foex@cmft.nhs.uk
\end{abstract}

Received 21 February 2014 Accepted 28 March 2014 Published Online First 16 April 2014

\begin{abstract}
This subjective review is based on a presentation made at the College of Emergency Medicine Scientific Conference in September 2013. My theme was that there are certain features of the critically ill which cause understandable anxiety, namely hypoxia, haemorrhage and hypotension. So, I have selected papers relevant to the management of these frightening situations.
\end{abstract}

\section{HYPOXIA}

Any hypoxic patient will receive oxygen therapy in the emergency department. In the first instance it will be through a facemask. If this fails to control the situation, continuous positive airway pressure (CPAP) may be used. If this fails, the patient will be intubated and ventilated invasively. But what tidal volume should be used? The 2000 ARDSnet study showed that low tidal volume ventilation was better than the tidal volumes previously used. ${ }^{1}$ In patients with adult respiratory distress syndrome (ARDS) there is a reduction in the volume of aerated lung, and the lungs are generally stiffer or less compliant than normal because of oedema. To ventilate these areas requires high pressures, but the result is that areas of relatively normal lung are over-inflated, which produces potentially damaging shear stresses. This can physically damage the alveoli and also provoke an inflammatory response with the production of inflammatory mediators. In this way mechanical ventilation may cause 'ventilator-induced lung injury'. The advantage of low tidal volume ventilation is that it reduces the extent of this.

\section{High frequency oscillation ventilation}

By extension, if we could use even lower tidal volumes so that there was even less inflation/deflation stress on the alveoli and the alveoli could be kept open, oxygenation would be maintained at a lower 'inflammatory cost'. This would allow the lungs to get better quicker and reduce mortality, or at least reduce the length of time on a ventilator. The most extreme 'low tidal volume ventilation' is high frequency oscillation ventilation (HFOV). This technique dates back to experiments in the 1970s. ${ }^{2}$

The development of ventilators that could deliver HFOV as well as conventional ventilation made this a practical reality and some intensive care units (ICUs) quickly adopted them for ARDS patients.

But would HFOV deliver the theoretical benefits? To answer the question, the Health Technology Assessment (HTA) programme funded the OSCAR trial, a UK multicentre trial, which ran from December 2007 until July 2012. ${ }^{3}$ Adults with ARDS (defined as having a $\mathrm{PaO}_{2} / \mathrm{FiO}_{2}<26.5 \mathrm{kPa}$ $(200 \mathrm{~mm} \mathrm{Hg})$ and four quadrant shadowing on the chest X-ray) were eligible if they had been ventilated for less than 7 days and were expected to need another $48 \mathrm{~h}$ of ventilation. They were randomised to receive either conventional ARDS ventilation or HFOV for up to 30 days. The primary outcome measure was 30-day all cause mortality. There were 166 deaths from the 398 in the HFOV group (41.7\%) compared with 163 deaths from 397 in the conventional ventilation group (41.1\%). When adjustments were made for study centre, gender, APACHE II score and the initial $\mathrm{PaO}_{2} / \mathrm{FiO}_{2}$ ratio, the OR for survival with conventional ventilation was 1.03 (95\% CI 0.75 to $1.4, p=0.87)$. So, HFOV was no better than conventional ventilation.

The OSCAR trial did not happen in isolation. In Canada, the OSCILLATE trial aimed to answer a similar question. ${ }^{4}$ The trial was slightly different in that it had a much stricter conventional ventilation protocol than OSCAR's very pragmatic approach. The OSCILLATE trial reported its results in the same issue of the New England Journal of Medicine and it made similarly poor reading for the HFOV enthusiasts. The trial was stopped early. Instead of the planned 1200 patients only 548 were randomised, with an in-hospital mortality rate of $47 \%$ in the HFOV group and $35 \%$ in the conventional ventilation group. The relative risk of death with HFOV was 1.33 (95\% CI 1.09 to $1.64, \mathrm{p}=0.005)$.

Prone ventilation

HFOV did actually improve oxygenation but did not improve survival. An alternative approach to improving oxygenation of the ventilated patients is to turn them prone. In many patients this will result in a marked improvement in oxygenation. However, the randomised controlled trials with mortality as an outcome stubbornly refused to show unequivocal benefit, but the meta-analyses suggested that there was still scope for further research. ${ }^{5}$ Earlier this year a paper was published which may finally answer the question. ${ }^{7}$ The entry criteria were more severe than for OSCAR with a $\mathrm{PaO}_{2} / \mathrm{FiO}_{2}$ ratio $<150 \mathrm{~mm} \mathrm{Hg}$ and patients were recruited earlier in the course of the disease. They also had a 12-24 h stabilisation period, because often as soon as a patient is intubated there are a few hours of persistent hypoxia. It often takes a few hours of positive pressure ventilation to recruit 
collapsed alveoli and see an improvement in oxygenation. Patients who respond in this way would no longer be regarded as suffering from ARDS. Enrolling them in a therapeutic trial would reduce the power of the trial, as they would all tend to get better and survive.

Over a 3-year period (January 2008-July 2011), 474 patients were randomised from 26 ICUs in France and one in Spain. Eight patients were excluded from the analysis: seven for breach of entry criteria and one because of 'guardianship issues'. Their primary outcome was all cause mortality at 28 days. In the prone group this was only $16 \%$, compared to $32.8 \%$ for the supine group $(\mathrm{p}<0.001)$. The HR for death with proning was only 0.39 (95\% CI 0.25 to 0.63 ), and this advantage was maintained at 90 days.

At last proning has been shown to do more than just improve oxygenation.

However, there remain concerns about the potentially life threatening complications inherent in turning a patient into the prone position, such as extubation, and dislodgement of other tubes and cannulae. Indeed, there were more extubations and tube obstructions in the prone group but this did not achieve statistical significance. There were more cardiac arrests in the supine group; presumably because patients in this group were more hypoxic.

\section{HAEMORRHAGE}

\section{Tranexamic acid}

Haemorrhage and haemorrhage control continue to be major challenges in the emergency department, the operating theatre and the ICU. The CRASH-2 trial showed that two doses of tranexamic acid reduced the mortality from trauma with a high risk of haemorrhage. ${ }^{8}$

Would tranexamic acid be of any benefit in preventing bleeding, or reducing bleeding during surgery? This question was addressed by an important meta-analysis published in the $B M J$ in 2012. ${ }^{9}$ The authors identified 129 trials between 1972 and 2011 , with a total of 10488 patients. Three trials were in emergency surgery and the remainder in elective situations. Eleven trials included children. The authors looked at the need for blood transfusion as a measure of the effect of tranexamic acid on bleeding. From 95 trials (7838 patients) in which this was reported, the authors calculated that the relative risk of a blood transfusion when tranexamic acid was given was 0.62 (95\% CI 0.58 to $0.65, \mathrm{p}<0.001)$ : a $38 \%$ risk reduction. When only the 32 trials with adequate concealment were included in the analysis, the risk reduction for blood transfusion was still $32 \%$. When the 69 trials with adequate blinding were analysed, the risk reduction was $37 \%$. Persuasive as these results are, the cumulative meta-analysis showed that the evidence for a benefit of tranexamic acid in reducing the risk of a blood transfusion in surgery has existed since 2001-2002. And yet, as the editorial in the $B M J$ pointed out, there are still small trials going on in different types of surgery addressing this very question. ${ }^{10}$

\section{Blood transfusion}

In January 2013, the cyclist Lance Armstrong finally admitted to blood doping, taking erythropoietin and various other banned drugs on the way to winning the Tour de France seven times. ${ }^{11}$ When it comes to endurance cycling, there is no doubt that blood is good for you. The same cannot be said for the critically ill. For over a decade, as a result of the Transfusion Requirement in Critical Care trial, we have accepted a haemoglobin of $70 \mathrm{~g} / \mathrm{L}$ as a transfusion threshold in the stable critically ill patient. ${ }^{12}$ That is not the case in goal-directed therapy for the resuscitation of the septic patient. ${ }^{13}$ So it was with great interest that I read a paper from Spain on transfusion strategies for acute upper gastrointestinal bleeding. ${ }^{14}$ The authors randomised patients admitted with acute upper gastrointestinal bleeding to either a restrictive transfusion strategy based on a haemoglobin threshold of $70 \mathrm{~g} / \mathrm{L}$ or a more liberal strategy based on a haemoglobin of $90 \mathrm{~g} / \mathrm{L}$. Patients were excluded if they were having a massive exsanguinating haemorrhage, although this was not precisely defined. Transfusions were allowed if there were symptoms of anaemia, there was massive bleeding or a surgical intervention was needed. Patients were stratified according to whether they had liver cirrhosis or not. Transfusions were with leucocyte-depleted blood. The primary outcome was all cause mortality at 45 days. Over the 6-year trial period, 921 patients were randomised. After 32 withdrawals there were 444 in the restrictive and 445 in the liberal strategy groups. Bleeding was caused by peptic ulcer disease in $49 \%$ and by varices in $21 \%$. Thirty one per cent of the patients had cirrhosis.

As might be expected, a higher proportion of the patients in the restrictive group received no transfusion compared to the liberal group ( $51 \%$ vs $14 \%, \mathrm{p}<0.001)$. Those in the restrictive group who did receive a transfusion received less than those in the liberal group $(1.5 \pm 2.3$ units vs $3.7 \pm 3.8$ units, $\mathrm{p}<0.001)$, but there were more protocol violations in the restrictive strategy group (9\% vs $3 \%, \mathrm{p}<0.001)$. Mortality at 45 days was significantly lower in the restrictive group compared to the liberal group ( $5 \%$ vs $9 \%, \mathrm{p}=0.02)$, and after adjustment for baseline risk factors the HR for death in the restrictive group was 0.55 (95\% CI 0.33 to 0.92 ). Subgroup analyses showed that the risk of death was lower in patients with peptic ulcer disease or cirrhosis (but not those with Child-Pugh C disease).

There were significantly fewer deaths from unsuccessful bleeding control in the restrictive strategy group $(0.7 \%$ vs $3.1 \%$, $\mathrm{p}=0.01)$, the re-bleeding rate was lower $(10 \%$ vs $16 \%, \mathrm{p}=0.01)$ and fewer rescue therapies were needed. The restrictive strategy was also associated with a shorter hospital length of stay, fewer transfusion reactions and fewer cardiac events. The number needed to treat to save one life at 45 days was 25 .

Is this paper a 'game-changer'? It is an important addition to the literature on situations when blood transfusions should be used cautiously. However, it is open to misinterpretation. The restrictive strategy was only applied to patients who were not exsanguinating and did not have symptoms of anaemia.

\section{HYPOTENSION}

\section{The downfall of starches}

If blood is not always the answer, which fluid should we use? In some respects the most important paper of 2013 for our practice could be said to be the European Medicine Agency's directive dated 14 June 2013: EMA/349341/2013, 'PRAC recommends suspending marketing authorisations for infusion solutions containing hydroxyethyl-starch'.

How did we get to this state of affairs? The debate about which intravenous fluids to use is almost as old as the intravenous technique itself. As early as 1880, Moutard-Martin and Richet noted that an intravenous injection of gum (a colloid) caused an increase in arterial pressure, but that an intravenous injection of a sugar solution merely resulted in polyuria. ${ }^{15}$ That different fluids might have different applications has been recognised for nearly a hundred years. Benjamin Moore, writing in the $B M J$ in October 1919 on 'The balance of colloid and crystalloid in cholera, shock and allied conditions' referred to two articles published the month before, and noted, "The second is a letter from Sir Leonard Rogers pointing out that while 
intravenous injections of hypertonic salines in cholera are of well proven advantage similar injections of gum arabic as used by Bayliss so effectually in combating wound shock, or surgical shock, are here of no avail but rather appear to be a disadvantage." 16 Moore went on to explain, "In the case of gum acacia in shock the colloidal 'solution aggregate' (colloidal molecule) is too large to pass out, and this retains crystalloid; these two together produce an osmotic pressure and keep up the volume of blood for the heart to drive round", and also acknowledged that "salines, given alone are here rapidly eliminated, having no colloid to anchor them, and so being treated as foreign bodies and thrown out by kidneys and intestines." Some of the detail of the explanation would no longer be regarded as valid, but the general concept was accepted for nearly a century.

A systematic review in 1998 suggested that there was a 4\% increase in mortality associated with the use of colloids in the critically ill. ${ }^{17}$ This study was heavily criticised by a profession still very sceptical of the systematic review and meta-analyses, and the result was largely ignored.

The spectre raised it head again in 2008 when Brunkhorst et $a l^{18}$ showed an increase in acute renal failure and the need for renal replacement therapy (RRT) in septic patients given starch, but we only really took on board the message that tight glycaemic control was of no benefit. Then in the last 18 months several studies and one scandal created a perfect storm, which resulted in the European Directive and other national recommendations to remove starches from our armamentarium.

Perner et $\mathrm{al}^{19}$ published a randomised controlled trial of $6 \%$ hydroxyethyl starch (HES) versus Ringer's lactate in adults with severe sepsis needing fluid resuscitation admitted to 26 Scandinavian ICUs between December 2009 and November 2011. They achieved their enrolment target and randomised 804 patients (798 analysed). The 90-day mortality rate was 51\% for the HES group versus $43 \%$ for the Ringer's lactate group (relative risk for HES $1.17,95 \%$ CI 1.01 to $1.36, p=0.03$ ); so, an $8 \%$ absolute increase in the risk of death with HES and a number needed to harm of 13 . There was also an increase in the need for RRT with HES (relative risk 1.35, 95\% CI 1.01 to $1.80, \mathrm{p}=0.04)$, a non-significant increase in the risk of severe bleeding, and no volume advantage.

Over a much longer period (December 2000-January 2012), 32 ICUs, under the guidance of the ANZICS Clinical Trials Group, were randomising adults admitted to the ICU and needing a fluid bolus in addition to their maintenance fluid requirement to receive either $6 \%$ HES or $0.9 \%$ saline. $^{20}$ Assuming a $26 \%$ baseline mortality rate for this varied ICU population, they estimated needing to randomise 7000 patients to detect a $3.5 \%$ absolute difference in 90-day mortality with $90 \%$ power. This they achieved. The primary outcome was available in 6651 patients. Mortality was less than expected and not significantly different in the two groups: $18 \%$ in the HES group and $17 \%$ in the saline group (relative risk with HES 1.06, 95\% CI 0.96 to $1.18, \mathrm{p}=0.26$ ). The need for RRT was greater in the HES group (7\% v 5.8\%)-relative risk 1.21 (95\% CI 1.0 to $1.45, \mathrm{p}=0.04)$ - and there were more adverse events, more blood products used, but less fluid.

To further inflame the debate it emerged that Joachim Boldt, until then one of the leading researchers in the field, had been guilty of systematic research fraud and that 88 of his published studies had been withdrawn from the literature. ${ }^{21}$ Would these retractions affect the debate? The Cochrane Systematic Review of 2013, which found no increase in mortality with HES (but no advantage either), concluded that the exclusion of the Boldt studies did not change this conclusion. ${ }^{22}$ Zarychanski et al, ${ }^{23}$ reviewing 38 trials (10 880patients), concluded that there was no increase in the risk of death in the critically ill resuscitated with HES. However, once the seven Boldt studies were removed (590 patients) there was an increase in the risk of death, the risk of renal failure and the need for RRT. Another systematic review and meta-analysis of nine trials with 3456 septic patients found that HES provided no mortality benefit. ${ }^{24}$ They also found there was a greater risk of acute kidney injury, more RRT, more blood transfusions and more adverse events with HES.

Against this background the European Medicine Agency's directive came as little surprise. It was followed by a position statement by the Faculty of Intensive Care Medicine, the Royal College of Anaesthetists, the Intensive Care Society and the College of Emergency Medicine supporting the European Medicine Agency's recommendation. ${ }^{25}$

\section{The intra-aortic balloon pump}

There are situations, such as cardiogenic shock after acute myocardial infarction (AMI), when giving fluid, or more fluid, is not the answer. Inotropes and/or vasopressors may improve things. But what about mechanical devices? The concept of aortic counterpulsation to augment coronary artery blood flow dates back to the 1950s and clinical trials in the 1970s. Although there was good evidence for an improvement in haemodynamics and for a reduction in infarct size in animal models, there was little evidence of a mortality benefit from trials. Nevertheless use of intra-aortic balloon pumps (IABPs) was recommended in both American and European guidelines for the management of cardiogenic shock after AMI in 2007-2008. ${ }^{26} 27$ Case series and cohort studies support the use of IABPs, but the randomised study by Thiele et $a l^{28}$ showed no benefit in 30-day mortality. In two meta-analyses in 2009, Sjauw et al showed that, from seven randomised trials, there was no benefit from IABPs in cardiogenic shock complicating AMI. In their second meta-analysis, of cohort studies, they found a slight increase in mortality $(6 \%)$ associated with the use of the IABPs when the AMI was managed with percutaneous coronary intervention (PCI). If the AMI was managed with just thrombolysis, there was an $18 \%$ reduction in 30-day mortality. Bahekar et $a l^{29}$ pooled all studies and concluded that there was an improvement in mortality with the IABPs (relative risk $0.72,95 \%$ CI 0.60 to $0.86, p<0.004$ ). Last year another meta-analysis, incorporating the latest trials, and again separating out the primary treatment for the AMI, confirmed an increase in mortality in patients whose primary treatment was PCI (relative risk 1.18, $\mathrm{p}=0.01$ ). ${ }^{30}$ When the primary treatment was thrombolysis, the risk of death was reduced with IABPs (relative risk $0.77, \mathrm{p}<0.001$ ). From these analyses it seems that the IABP only has a role in the management of cardiogenic shock when PCI is either not available or contraindicated. The most recent guidelines have acknowledged that the evidence for IABPs is weaker than previously stated. ${ }^{31} 32$

\section{Staffing}

There is much talk about consultants working throughout the day and night in emergency departments. It almost goes without saying that this will improve the quality of care. Is there evidence for this? An observational study a few years ago suggested that in ICUs run by intensivists, and well staffed during the day, having an additional attending intensivist at night did not reduce mortality. ${ }^{33}$ To add to this literature, last year, the results of the SUNSET-ICU (Study to Understand Night-time Staffing Effectiveness in a Tertiary Care ICU) trial were published. ${ }^{34}$ This was a randomised trial in a 24-bedded medical ICU. The year was divided into 7-night blocks and each block was 
randomly allocated to have a resident board-certified intensivist in addition to the three medical residents (intervention) or to have just the three residents and have the intensivist on-call from home (control). The primary outcome was ICU length of stay. Median length of stay was 52.7 hours. This was not affected by night-time staffing, even for those patients admitted at night. There was no effect on hospital length of stay, ICU mortality, hospital mortality, readmission to ICU, or even discharge home. Although $61 \%$ of their admissions were at night the authors admitted that they had experienced residents covering the nights and very good staffing during the day. In this setting the processes of care may be such that the addition of an attending physician at night adds little to patient care. There may be other valid reasons for this model of staffing, such as improved training of juniors, better support of nursing staff and improved communication with families. These results will not be valid for emergency medicine, but they do highlight the fact that what may seem obvious may not stand up to rigorous evaluation.

\section{Gizmo idolatry}

Occasionally one reads an article, which really makes one think. 'Gizmo idolatry', by Leff and Finucane, was just that. ${ }^{35}$ They write, "gizmo idolatry refers to the general implicit conviction that a more technological approach is intrinsically better than one that is less technological unless, or perhaps even if, there is strong evidence to the contrary." The authors go on to list drivers to adopt new technologies. These include common sense appeal, a love for machines, the attractiveness of the 'exploit' over 'uneventful diligence', the gizmo as proof of competence or even excellence, use of the gizmo as proof against negligence, and as a source of measurable data. One can think of a number of interventions, which may fall into this category: HFOV and nitric oxide in the management of ARDS, the pulmonary artery flotation catheter, the IABP, MRI scans for simple back pain, to name but a few. Then there is the use of expensive new drugs or their formulations over well-established versions. How many patients need intravenous paracetamol rather than the oral preparation? Gizmo idolatry highlights the importance of randomised controlled trials, systematic reviews and meta-analyses in the evaluation of new techniques.

\section{SUMMARY}

In the last 18 months clinical trials and meta-analyses have steered some important advances in the management of the critically ill. They have also revealed what might appear to be examples of 'gizmo idolatry'. There is now good evidence for prone ventilation in severe hypoxia. On the other hand, HFOV has not been shown to reduce mortality. Tranexamic acid does reduce the need for blood transfusions in surgical patients and there is now some evidence in favour of a more restrictive blood transfusion strategy in upper gastrointestinal haemorrhage. There has been a major change in the fluids used in volume resuscitation of the critically ill. Several large multicentre studies and meta-analyses have prompted a re-evaluation of the use of hydroxyethyl starches by showing that, at best, there is no survival advantage to using them, but at worst there is an increased risk of death and renal failure, and they are more expensive than crystalloids. A mechanical approach to managing hypotension after myocardial infarction, the intra-aortic balloon pump, also seems to confer little benefit where PCI is available.

While it is now widely accepted that patient care in the NHS would be improved by increasing consultant presence at nights and at weekends, the evidence from the SUNSET-ICU trial in the USA suggests that this may not be true in a well-staffed ICU. All of which underline the importance of evidence-based practice as an antidote to gizmo idolatry.

Correction notice This article has been corrected since it was published Online First. The title of 'Professor' was removed from the correspondence section.

Competing interests None.

Provenance and peer review Commissioned; externally peer reviewed.

\section{REFERENCES}

1 The Acute Respiratory Distress Syndrome Network. Ventilation with lower tidal volumes as compared with traditional tidal volumes for acute lung injury and the acute respiratory distress syndrome. N Engl J Med 2000;342:1301-8.

2 Lunkenheimer PP, Rafflenebell W, Keller $\mathrm{H}$, et al. Application of transtracheal pressure oscillations as a modification of 'diffusion respiration'. Br J Anaesth 1972;44:627.

3 Young D, Lamb SE, Shah $S$, et al. High-frequency oscillation for acute respiratory distress syndrome. N Engl J Med 2013;368:806-13.

4 Ferguson ND, Cook DJ, Guyatt GH, et al. High-frequency oscillation in early acute respiratory distress syndrome. N Engl J Med 2013;368:795-805.

5 Sud S, Friedrich JO, Taccone $P$, et al. Prone ventilation reduces mortality in patients with acute respiratory failure and severe hypoxemia: systematic review and meta-analysis. Intensive Care Med 2010;36:585-99.

6 Abroug F, Ouanes-Besbes L, Dachraoui F, et al. An updated study-level meta-analysis of randomised controlled trials on proning in ARDS and acute lung injury. Crit Care 2011;15:R6.

7 Guerin C, Reignier J, Richard J-C, et al. Prone positioning in severe acute respiratory distress syndrome. N Engl J Med 2013;368:2159-68.

8 CRASH-2 trial collaborators. Effects of tranexamic acid on death, vascular occlusive events, and blood transfusion in trauma patients with significant haemorrhage (CRASH-2): a randomised, placebo-controlled trial. Lancet 2010;376:23-32.

9 Ker K, Edwards P, Perel $P$, et al. Effect of tranexamic acid on surgical bleeding: systematic review and cumulative meta-analysis. BMJ 2012;344:e3054.

10 Godlee F. Are we nearly there with tranexamic acid? BMJ 2012;344:e3665

11 Fotheringham W. Lance Armstrong's Oprah confession was all about the f-word: flawed. http://www.theguardian.com/sport/2013/jan/18/lance-armstrong-confessionfword-flawed (accessed 24 Jan 2014).

12 Hébert PC, Wells G, Blajchman MA, et al. A multicenter, randomized, controlled clinical trial of transfusion requirements in critical care. $N$ Engl J Med 1999:340:409-17.

13 Rivers E, Blake HC, Dereczyk B, et al. Early goal-directed therapy in the treatment of severe sepsis and septic shock. N Engl J Med 2001;345:1368-77.

14 Villanueva C, Colomo A, Bosch A, et al. Transfusion strategies for acute upper gastrointestinal bleeding. N Engl J Med 2013;368:11-21.

15 Moutard-Martin R, Richet C. Effects of intravenous injection of sugar and gum. Lancet 1880;1:182.

16 Moore B. The balance of colloid and crystalloid in cholera, shock, and allied conditions. BMJ 1919;2:490-2.

17 Schierhout G, Roberts I. Fluid resuscitation with colloid or crystalloid solutions in critically ill patients: a systematic review of randomised trials. BMJ 1998;316:961-4.

18 Brunkhorst FM, Engel C, Bloos F, et al. Intensive Insulin Therapy and Pentastarch Resuscitation in Severe Sepsis. New Engl J Med 2008;358:125-39.

19 Perner A, Haase N, Guttormsen AB, et al. Hydroxyethyl starch 130/0.42 versus Ringer's acetate in severe sepsis. N Engl J Med 2012;367:124-34.

20 Myburgh JA, Finfer S, Bellomo R, et al. Hydroxyethyl starch or saline for fluid resuscitation in intensive care. N Engl J Med 2012;367:1901-11.

21 Wise J. Boldt: the great pretender. BMJ 2013;346:f1738.

22 Perel P, Roberts I, Ker K. Colloids versus crystalloids for fluid resuscitation in critically ill patients. Cochrane Database of Systematic Reviews 2013;(2):CD000567.

23 Zarychanski R, Abou-Setta AM, Turgeon AF, et al. Association of hydroxyethyl starch administration with mortality and acute kidney injury in critically ill patients requiring volume resuscitation: a systematic review and meta-analysis. JAMA 2013;309:678-88.

24 Haase N, Perner A, Hennings LI, et al. Hydroxyethyl starch 130/0.38-0.45 versus crystalloid or albumin in patients with sepsis: systematic review with meta-analysis and trial sequential analysis. BMJ 2013;346:f839.

25 FICM. Position statement by the Faculty of Intensive Care Medicine, the Royal College of Anaesthetists, the Intensive Care Society and the College of Emergency Medicine. 2013. 28/01/2013. http://www.ficm.ac.uk/sites/default/files/Suspension of HES Products 20Jun13.pdf.

26 Anderson JL, Adams CD, Antman EM, et al. ACC/AHA 2007 guidelines for the management of patients with unstable Angina/Non-ST-elevation myocardial infarction: a report of the American College of Cardiology/American Heart Association Task Force on Practice Guidelines (Writing Committee to Revise the 2002 Guidelines for the Management of Patients With Unstable Angina/Non 
ST-Elevation Myocardial Infarction): developed in collaboration with the American College of Emergency Physicians, the Society for Cardiovascular Angiography and Interventions, and the Society of Thoracic Surgeons: endorsed by the American Association of Cardiovascular and Pulmonary Rehabilitation and the Society for Academic Emergency Medicine. Circulation 2007;116:e148-304.

27 Van de Werf F, Bax J, Betriu A, et al. Management of acute myocardial infarction in patients presenting with persistent ST-segment elevation: the Task Force on the management of ST-segment elevation acute myocardial infarction of the European Society of Cardiology. Eur Heart I 2008;29:2909-45.

28 Thiele H, Zeymer U, Neumann F-J, et al. Intraaortic balloon support for myocardial infarction with cardiogenic shock. N Engl J Med 2012;367:1287-96.

29 Bahekar A, Singh M, Singh S, et al. Cardiovascular outcomes using intra-aortic balloon pump in high-risk acute myocardial infarction with or without cardiogenic shock: a meta-analysis. J Cardiovasc Pharmacol Ther 2012;17:44-56.

30 Romeo F, Acconia MC, Sergi D, et al. The outcome of intra-aortic balloon pump support in acute myocardial infarction complicated by cardiogenic shock according to the type of revascularisation: a comprehensive meta-analysis. Am Heart J 2013;165:679-92.

31 O'Gara PT, Kushner FG, Ascheim DD, et al. 2013 ACCF/AHA guideline for the management of ST-elevation myocardial infarction: a report of the American College of Cardiology Foundation/American Heart Association Task Force on Practice Guidelines. Circulation 2013;127:e362-425.

32 Steg PG, James SK, Atar D, et al. ESC Guidelines for the management of acute myocardial infarction in patients presenting with ST-segment elevation: The Task Force on the management of ST-segment elevation acute myocardial infarction of the European Society of Cardiology (ESC). Eur Heart J 2012;33:2569-619.

33 Wallace DJ, Angus $D$, Barnato $A E$, et al. Nighttime intensivist staffing and mortality among critically ill patients. N Engl J Med 2012;366:2093-101.

34 Kerlin MP, Small DS, Cooney E, et al. A randomized trial of nighttime physician staffing in an intensive care unit. N Engl J Med 2013;368:2201-9.

35 Leff B, Finucane TE. Gizmo idolatry. JAMA 2008;299:1830-2. 